\title{
HACIA LA CONSTRUCCIÓN DE UN MARCO HISTÓRICO DE REFERENCIA PARA EL ESTUDIO DE LA ENSEÑANZA DE LAS LETRAS EN EL SIGLO XIX CHILENO*
}

\author{
Edda Hurtado P.*
}

\begin{abstract}
Resumen
En este trabajo se revisa panorámicamente el periodo de la historia política y cultural chilena entre 1830 y 1860 para avanzar en un marco de referencia que permita observar las incipientes intervenciones y regulaciones institucionales cuyos cruces marcaron el devenir político, social y cultural en relación con la enseñanza de las letras en el ámbito escolar del periodo. Este progresivo aunque lento desarrollo se caracterizó por una activa participación de los letrados de la elite gobernante en debates y decisiones que contenían en su núcleo la discusión en torno a qué saberes se necesitaban para formar al ciudadano de la república. Estos debates se realizaron en tribunas extra- escolares cuyos intentos apuntaban a definir a quién enseñar (ciudadano) y qué enseñar (saberes escolares).
\end{abstract}

Palabras Clave: siglo XIX, enseñanza de las letras, políticas lingüísticas, ciudadanía.

\section{TOWARDS THE CONSTRUCTION OF A HISTORICAL FRAME \\ OF REFERENCE FOR THE STUDY OF THE TEACHING OF THE LETTERS IN THE NINETEENTH CENTURY CHILE.}

\begin{abstract}
In this paper we discuss a panoramic view of the cultural and political chilean history for the period between 1830 and 1860 to proceed in a framework which allows to observe the emerging interventions and institutional regulations whose crosses marked the political, social and cultural future related to literature teaching at schools in the period. This progressive though slow development was characterized by an active participation of intellectuals belonging to the ruling elite in debates and decisions containing the core discussion about what knowledge was needed to form the citizen of the republic. These debates were carried out in extra school places whose attempts were directed to define whom to teach to (citizen) and what to teach (school knowledge).
\end{abstract}

Keys words: Key words: nineteenth century, literature teaching, linguistic policies, citizenship.

* Este artículo forma parte de una investigación realizada en el marco del Proyecto Fondecyt de Iniciación 2012, $\mathrm{N}^{\circ}$ 11121296: Literatura y Educación: continuidades y rupturas en la progresiva conformación de un discurso especifico acerca de la enseñanza literaria en Chile en los inicios del sistema republicano (1842-1893).

** Chilena, Doctora en Literatura, Pontificia Universidad Católica de Valparaíso, Chile. edda.hurtado@ ucv.cl 
En Chile somos esencialmente patriotas: tenemos la furia del patriotismo, que es una de las tantas enfermedades heroicas que sufren los pueblos jóvenes, sin tradiciones, con un pasado nuevo y que todo lo aguardan de su propia fuerza, de su virilidad ... Y conozco gentes cuya vida no es más que una perpetua canción nacional, cantada en todos los tonos imaginables, pero sin acompañamiento de música.

Estudios y ensayos literarios, 1889.

Pedro Balmaceda Toro.

La obra de Portales fue la restauración de un hecho y un sentimiento, que habían servido de base a1 orden público, durante la paz de siglos octaviana de los tres de la colonia: el hecho, era la existencia de un Poder fuerte y duradero, superior a1 prestigio de un caudillo o a la fuerza de una facción; el sentimiento era el respeto tradicional por la autoridad en abstracto, el Poder legítimamente establecido con independencia de quienes lo ejercían. Su idea era nueva de puro vieja: lo que hizo fue restaurar material y moralmente la monarquía, no en su principio dinástico, que ello habría sido ridículo e imposible, sino en sus fundamentos espirituales como fuerza conservadora del orden y de las instituciones.

La Fronda Aristocrática, 1928.

Alberto Edwards.

De los dos breves comentarios anteriores se consolida algo así como una suerte de mito: Diego Portales estableció las bases de la NaciónEstado del Chile que perduró más allá del siglo XIX. Pero la ironía de ambas citas amplifica y a la vez destraba un poco ese mito. Por una parte, la cita de Pedro Balmaceda nos sugiere que la fronda de la banda política cantó mucho pero casi sin ninguna ruptura con la música existente del orden social. Por su parte Edwards, profundiza más el leiv motiv de Portales para la nación: restaurar el orden colonial pero no bajo el vals monárquico, danzando el himno de la república traída desde Europa. En definitiva, su proyecto era tan nuevo de puro viejo. Pero a pesar de cualquier ironía o sarcasmo -que son bastante comunes en la expansión liberal- historiadores de época -antiguos o recientes- y de diversas tendencias con rigor y seriedad, ven en Portales y su proyecto el eje de la relación Estado-sociedad durante todo el siglo XIX. Y su análisis, más allá 
de los tonos que le impriman, cruza y conmueve todos los ámbitos que enmarcan el devenir del país, tanto material como cultural.

En lo que concierne a la educación y la enseñanza de las letras, sus efectos, si bien parecen distantes, son siempre dignos de re-examinar. Más aún si tenemos en cuenta el devenir de una sociedad en la modernidad según P. Bourdieu, quien establece que si todos los campos económicos y sociales tienden a producir la generación de bienes y de roles para la diversidad de grupos sociales de una nación, la educación misma no es sino un mecanismo de reproducción de ese devenir incremental, pero con una singularidad que marca la ligazón de los procesos "productivos / reproductivos": el poder social dominante que los hace circular en un mismo rodaje. Sus efectos y resultados aunque visibles son de alguna manera algo velados por el mecanismo de "reproducción": que el capital económico y social fluya hacia el mismo núcleo que lo produce, incluyendo el propio capital "simbólico" [cultural]. En otras palabras, la educación en tanto proceso reproductivo contribuye a que los grupos que participan en la producción mantengan su misma identidad, roles y capital económico / social/simbólico, incluso considerando que la producción capitalista en su despliegue de más de dos siglos fue adquiriendo y aumentando un dinamismo versátil y flexible y su reproducción sigue sin alterar la lógica que anima su pulsión incremental.

En el escenario nacional de principios del XIX, distinguimos al menos cuatro problemas en el campo educacional entre los decenios de 1830 a 1860. Tema que incluso hoy es acreditado como la matriz que genera o des-genera el nivel de capital educativo o simbólico del que gozan los alumnos y con eso, el desequilibrio o equilibrio que puede ostentar nuestra sociedad. A continuación, acotamos brevemente esos cuatro problemas.

Primero: Bourdieu realiza sus investigaciones en un capitalismo avanzado que ya ha dejado muy atrás su fase industrial y transita velozmente en su fase financiera en vías a su globalización. Por lo mismo, su análisis puede regir, con alteraciones adecuadas, a naciones de desarrollo con horizonte de "emergentes"; sin embargo, nuestro caso histórico-social es distante. Se trata de un capitalismo en su primer desarrollo, donde en el norte-occidental solo muy pocas naciones comenzaban su ascendencia, otras lo hacían en forma limitada, y las demás ni siquiera afloraban al mercado. Con toda razón, el proceso de 
educación "reproductiva" se encontraba en el inicio de su construcción. Entonces, en el Chile naciente de la década del 30 surge la interrogante: ¿Cuál es el esquema educativo que se ejecutaba con mayor o menor eficacia en la realidad?

Segundo: para la mayoría de los historiadores el proyecto y eje portaliano se centraba en el autoritarismo y en la centralidad de gobernar y administrar el Estado y la sociedad, incluso algunos ratificaban una línea portaleana de restauración de los elementos claves de la antigua colonia hispana pero esta vez en el cuadro formal de la república independiente. Visto así, en términos de restauración con apariencia renovada del orden social y político ¿Cómo funcionó en la realidad no discursiva el mecanismo reproductivo de la educación y en especial de la enseñanza primaria? ¿Ese mecanismo primario y primordial reproducía el orden colonial o algo del desorden republicano o, por el contrario, se logró establecer un consenso intermedio que escapara a ambos extremos?

Tercero: si en la realidad ese sistema de enseñanza reproducía en mayor o menor grado el orden colonial ¿existieron tendencias opuestas, como la liberal, que se opusieran tenazmente a ese orden de estirpe reaccionaria?

Cuarto: en América Latina la independencia republicana con signos de liberalismo llegó tarde y en la mayoría de los casos se tradujo en caudillismos con no pocas tiranías. De ahí, que el capitalismo en desarrollo retomara una tradición del antiguo régimen: el colonialismo pero sólo extractivo de productos para sus industrias. Por lo mismo, Chile pertenecía [aún] a esa zona periférica de un capitalismo occidental en desarrollo. Sin embargo, a treinta años de asentada su independencia, y tras dos décadas de conmociones -el divisionismo caótico de los independentistas y el autoritarismo portaliano- Chile aparecía ya como un país próspero y confiable para las naciones encumbradas en su capitalismo. Lo que acreditaba, desde afuera, esa garantía era su orden interno, su atinada Constitución que fijaba sus deberes fundamentales, su eficaz división administrativa y una élite culta e ilustrada. Por lo tanto, la interrogante es insoslayable: en una sociedad que hacia 1830 se debatía entre el caos o el autoritarismo ¿qué pasó en el ámbito educacional para que a Chile se lo considerara como nación ordenada y confiable?

Sin adentrarnos del todo en la sociología ni en la historiografía, pretendemos adelantar un "socioanálisis histórico" basándonos en

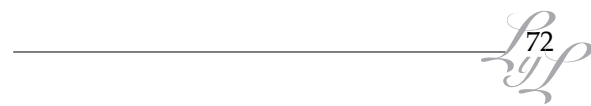


la rigurosa mirada de Bourdieu que nos permite elaborar ficción metodológica que avale una mirada oblicua sobre ciertas señales de la educación primaria en casi 30 años -1830 a 1860- para vislumbrar algo del escenario de polémicas que exhiben desencuentros y encuentros entre las tendencias políticas rivales. De ahí la forma y la intención de este breve artículo: repasar el proyecto portaliano en su ejecución por el propio Diego Portales y por sus herederos en su liderazgo como lo son Manuel Montt y Andrés Bello. Y en ese marco, explorar, con los datos que tenemos y hemos registrado sobre el discurrir de la enseñanza primaria, en un periodo que abarca desde 1830 hasta 1860, fin del denominado "ciclo conservador".

En primer lugar nos parece certera la interpretación del historiador Mario Góngora sobre el gobierno y el ciclo de Portales que desde 1830 cruza todo el siglo XIX. Su signo inicial es elocuente: la concepción fundamental de Portales, "consiste en restaurar una idea nueva de puro vieja, a saber, la de la obediencia incondicional de los súbditos a $a^{1}$ Rey de España, durante la Época colonial. Ahora se implantaba una nueva obediencia, dirigida hacia quien ejerciera la autoridad, legítima en cuanto legal" (Góngora, 12).

Los hechos son significativos. Después de 1819, donde los revolucionarios se basaban en todas las nociones peculiares del Estado tradicional europeo, pero expresadas en el lenguaje de la Ilustración, hacia 1823 esa naciente república entró en crisis y de ahí al caos entre las divisiones internas por parte de los independentistas, emergiendo un nuevo grupo, que a pesar de ser republicano era plenamente conservador por su "dignidad y propiedad social". Tras la batalla de Lircay entre Freire y Prieto, este último se queda con el poder del gobierno, con Portales como ministro. El carácter de este nuevo ciclo que surge hacia 1830 es visto por Góngora como el momento en que se desarrolla

un gobierno fuerte, extraño al militarismo y al caudillismo de los tiempos de la Independencia, que proclama en la Constitución de 1833 que Chile es una República democrática representativa, y que afirma su legitimidad en quien ha sido elegido según un mecanismo legal, y que rige $\mathrm{a}^{1}$ país según

1 Citamos sobre este tema el libro de Ana María Stuven V., La seducción de un orden. 
esas normas legales. [...] la especifica concepción "portaliana" consiste en que realmente Chile no poseela "virtud republicana" que, desde Montesquieu y la Revolución Francesa, se afirmaba ser indispensable para un sistema democrático, de suerte que la Democracia debe ser postergada, gobernando, entretanto, autoritariamente pero con celo del bien público, hombres capaces de entenderlo y realizarlo. (Góngora, 12)

En rigor esa es la actitud de Portales en 1822, cuando en una carta a Cea, su socio del estanco del tabaco, expresa que sólo confía en un gobierno fuerte y centralizado. $Y$ eso es lo que hace como ministro del presidente Prieto. Según Góngora, "los textos legales, la misma Constitución de 1833, le importaban poco: obligatorios para 1os simples ciudadanos, los funcionarios y los tribunales de justicia, esos textos tenían que dejar cabida para la discrecionalidad del jefe del Poder Ejecutivo, cuando así lo [exigiera] el bien público" (Góngora, 12). Este firme dispositivo propio del poder de la nación, lo convirtió en un fundador que rehusó las visibilidades prestigiosas pero fortaleció la eficacia de sus acciones; visto así, Portales se erigió como una "eminencia gris" y no como un caudillo, utilizando su poder tras la figura de Prieto, cuya Presidencia aseguró durante dos quinquenios. Sin embargo, Portales como "eminencia gris" poseía una suerte de ética, cuyos términos señala el propio Góngora:

Pienso, por el contrario, que para Portales "el principal resorte de la máquina" era la distinción entre los que él llama en sus cartas "los buenos" y "los malos". Los "buenos" son "los hombres de orden", "los hombres de juicio y que piensan", "los hombres de conocido juicio, de notorio amor al país y de las mejores intenciones". Los "malos", sobre quienes debe recaer el rigor absoluto de la ley, son "los forajidos", "los lesos y bellacos", aludiendo sin duda a los pipiolos y los conspiradores de cualquier bando. Lamenta a veces la tibieza en el Gobierno y aun de aquellos que son afectos al Gobierno "por su natural propensión a1 orden y la paz", "todas las piezas de la maquina se van desencajando sensiblemente", "porque los malos no le tienen respeto" al Gobierno. (Góngora, 13-14)

¿Y en qué consiste la ética de Portales? Alberto Edwards con un solo episodio la reseña: al vaticinar que Prieto será ganador, Portales piensa y luego ejecuta expulsar a toda la oficialidad independentista 
liberal, esto es a la mitad del Ejército, al mismo tiempo que se forma una guardia nacional igual a las milicias de la colonia, y la sociedad queda jerárquicamente armada frente a una posible resurrección de militares liberales. Por lo mismo, aún antes de la batalla de Lircay, todo el grupo aristocrático pasa a formar parte del círculo estrecho de Portales y se agrupa temeroso en torno suyo celebrando sus audacias que presagian el éxito común, sin advertir que se les está reduciendo a ellos mismos también a la impotencia (Edwards, 48 y sgts). Refiriéndose a la fracción aristocrática que lidera al grupo dominante, Portales escribe en una de sus cartas:

“... Nadie quiere vivir sin el apoyo del elefante blanco del Gobierno y cuando los huevones y las putas no son satisfechos en sus caprichos, los pipiolos son unos dignos caballeros al lado de estos cojudos. Las familias de rango de la capital, todas jodidas, beatas y malas, obran con un peso enorme para la buena marcha de la administración" (Portales, 1831).

Con todo y pese a controlar a la aristocracia terrateniente, Portales "presupone que la aristocracia es la clase en que se identifica el rango social, y todos sus intereses anexos, con la cualidad moral de preferir el orden público al caos. Esto sería "el principal resorte de la 'máquina' en el portalianismo, a nuestro juicio" (Góngora, 16). Esto otorga el nivel y la dignidad del orden que impone Portales.

Por lo pronto, en el gobierno de Manuel Bulnes (1841-1851) todos los círculos letrados -aunque fuesen contestatarios al régimen- durante esa década incrementaron sustancialmente los periódicos y revistas nacionales, medios impresos cada uno de los cuales tenía su comité editor e intelectuales permanentes que como articulistas y cronistas animaban una abierta pero estrecha "libertad de expresión". Al mismo tiempo, la misma sociedad civil letrada comienza a formar sus instituciones como espacios de discusión. Entre otras, la Sociedad Literaria, fundada en 1842, presidida por Anacleto Montt y conformada por alumnos selectos del Instituto Nacional, donde José Victorino Lastarria pronuncia su discurso inaugural.

Una sociedad civil letrada estrecha pero también con fisura de 'apertura'. Sus signos son evidentes. En primer lugar, porque emergen los nuevos liberales que paulatinamente ganan más espacio en el "mercado de las letras" que hasta no hace mucho era un sólido e inabordable piso 
político-cultural. A lo anterior, se suman intelectuales latinoamericanos cuya primera figura es el venezolano Andrés Bello que llega a Chile en 1829. Nueve años más tarde, llegó al país el geólogo polaco Ignacio Domeyko, y en 1841 lo hace un contingente no menor de argentinos progresistas escapando del gobierno de Juan Manuel de Rosas. Entre ellos, y desde su arribo, Domingo Faustino Sarmiento constituyó una mano prominente en la prensa chilena, seguido por otros de sus compatriotas: Mitre, López y Alberti.

Como lo han afirmado varios historiadores chilenos tanto desde fines del siglo XIX hasta las recientes investigaciones historiográficas, el año 1842 "instauró un nuevo horizonte de futuro" para una nación fracturada por su reciente pasado. Y su eje fueron las tensiones ideológicas que afloraron en el nuevo escenario político que comenzaba a construirse dentro de la élite social. Por una parte, los conservadores, herederos y administradores del proyecto portaliano; por otra, los emergentes liberales que buscaban instaurar en propiedad una república independiente, libre y soberana. Por lo mismo, una de sus confrontaciones será romper con una enfermedad del cuerpo social, que todavía se encontraba flagelado por la dominación colonial, donde una republicana élite-oligarca mantenía su poder dominando y sometiendo a una plebe bajo condiciones de una ignorante esclavitud. En esa aspiración, los nuevos liberales buscaron romper con el pasado colonial, desmantelar de la nación soberana todo autoritarismo y asumir el derecho de educar a los ciudadanos bajo todos los deberes republicanos de libertad y soberanía. Como contraparte, los conservadores portalianos defendían la sólida unidad del país, su eficiente gobernabilidad sin ninguna alteración, la irreprochable división de los poderes del Estado, y la bonanza mercantil que experimentaba Chile producto de sus vínculos con las potencias de nueva economía -capitalismo- que comenzaba a imperar en Occidente. 


\section{¿Qué enseñar al ciudadano de la nueva nación? La primera polémica: Domingo Faustino Sarmiento y Andrés Bello.}

En el cambio de escenario de la élite letrada, se iniciaron sucesivas confrontaciones en los medios de expresión que en poco tiempo devinieron en un tenso e intenso "cuadro de polémicas" sobre las cuales diversos investigadores han aportado notables análisis1. Y no es inusual que en este "cuadro de polémicas", muy pronto ese "obscuro objeto de deseo" de los liberales fuera la educación, apoyo constante del poder de los conservadores. En esa tenaz confrontación, el escenario se modificó. Entre los conservadores, junto al sólido partidario del orden que es Andrés Bello, estaba en el poder, Manuel Montt, en ese momento Ministro de Justicia, Culto e Instrucción Pública de Manuel Bulnes. En la tendencia liberal Domingo Faustino Sarmiento, y José Victorino Lastarria. Sin embargo, en ambas tendencias y en sus fracciones, parecía dominar un imperativo categórico: la prosperidad y bienestar material y cultural de la nación. En ese sentido, el juicio para esos años de Sol Serrano es certero en cuanto a la evidencias de los impulsos de la élite letrada: "se abre una etapa de resplandor intelectual y político" (Serrano, 87).

Dos polémicas particularmente importantes se desarrollan en ese periodo: la intercambiada en la prensa, básicamente entre Sarmiento y Bello en 1841-42 y la segunda, en el marco de medios oficiales y de prensa, entre 1844 y 47-8, entre Lastarria y Bello.

La primera de estas dos polémicas ${ }^{2}$, siguiendo un breve diagrama textual de esta larga y tensionada confrontación, puso en escena la provocación inicial llevada a cabo por Sarmiento a mediados de 1841 reprochando a la juventud chilena su pereza y encogimiento para cultivar la literatura, que solo seguía la norma del modelo clásico. Aunque el diagnóstico de Sarmiento omitía explicitar inicialmente a quien iban dirigidas sus observaciones, claramente se refería a la máxima autoridad humanista y de política literaria que establecía el canon de las letras en el país: Andrés Bello. Si bien muchos intelectuales chilenos respondieron a

2 Junto al aporte de la obra anterior de Stuven, destacamos muy especialmente el análisis de esta polémica de Iván Jaksic en su notable obra Andrés Bello: La pasión por el orden. Si bien nuestra conclusión no se ajusta a la de Jaksic, su lineamento de esta polémica y de todo su libro constituye una nueva perspectiva a la obra de Bello y de su entorno del XIX 
Sarmiento ${ }^{3}$, Bello sólo expresó su opinión en El Araucano en noviembre de 1841, y lo hace en utilizando en estos términos:

En literatura, los clásicos y románticos tienen cierta semejanza no lejana con lo que son en política los legitimistas y los liberales. Mientras que para los primeros es inapelable la autoridad de las doctrinas y prácticas que llevan el sello de la antigüedad, y el dar un paso fuera de aquellos trillados senderos es rebelarse contra los sanos principios, los segundos, en su conato a emancipar el ingenio de trabas inútiles, y por lo mismo perniciosas, confunden a veces la libertad con la más desenfrenada licencia. (Bello, 1841)

Para hacer más concisa y directa nuestra línea de percepción, lo primero que se debate en esta "polémica" (Jaksic, 195) constituye un eje sobre política literaria: la diferencia y oposición entre "clasicismo" y "romanticismo", cuyos efectos y resonancias en Chile perdurarán hasta la década de los años 80 del XIX. Lo segundo, obedece a un inesperado giro que asume el debate: ya no se habla de política de literatura sino de la política de la lengua de las repúblicas independientes. Es el propio Sarmiento quien en abril de 1842, profundiza el tema de la literatura pasando a su matriz original: la lengua y la soberanía de los pueblos independientes, esa identidad idiomática aun si -como subraya Jaksicsignificara un conflicto con la autoridad de los expertos:

La soberanía del pueblo tiene todo su valor i su predominio en el idioma; los gramático son como el senado conservador, creados para resistir los embates populares, para conservar la rutina i las tradiciones. Son a nuestro juicio, si nos perdonan la mala palabra, el partido retrógrado, estacionario, de la sociedad habladora; pero como los de su clase en política, su derecho está reducido a gritar i desternillarse contra la corrupción, contra los abusos, contra las innovaciones. (Sarmiento, 1842) ${ }^{4}$.

Sin ningún desvío la argumentación de Sarmiento se dirigía y se clavaba en el centro de la autoridad máxima de lengua nacional: otra vez Andrés Bello. Y en circunstancias que no toleraban la mínima

11 En nuestra consideración y de otros autores, la llamada "polémica" constituye una "género" de expresión con variedad de líneas que van desde la "confrontación de mini-ensayos" salpicado de "literatura" propia o ajenas.

12 Citamos sobre este tema el libro de Ana María Stuven V., "La seducción de un orden". 
ambigüedad. Como expresa Jaksic, Bello ${ }^{5}$ defendía el buen uso de la lengua desde 1830, y recién en 1841, publicó su Análisis ideológica sobre el verbo castellano. Entonces, sin mediar pausa alguna, Bello contestó públicamente el 12 de mayo de 1842:

¿Cómo podría permitirse al pueblo la formación a su antojo del lenguaje, resultando que cada cual vendría a tener el suyo, y concluiríamos por otra Babel? en las lenguas como en la política, es indispensable que haya un cuerpo de sabios, que así dicte las leyes convenientes a sus necesidades, como las del habla en que ha de expresarlas; y no sería menos ridículo confiar al pueblo la decisión de sus leyes, que autorizarle en la formación del idioma. En vano claman por esa libertad romántico-licenciosa del lenguaje, los que por prurito de la novedad, o por eximirse del trabajo de estudiar su lengua, quisieran hablar y escribir a su discreción ${ }^{6}$ (Jaksic, 2001: 178).

A ese nivel, la disputa entre Sarmiento y Bello causó conmoción en la elite letrada, implicando a los incumbentes de Bello y a los compatriotas de Sarmiento que en poco tiempo gozaban de tribunas ya reconocidas por algunos liberales nacionales en la prensa chilena. Sin embargo dos líneas, de diferente índole y grosor político, cambiaron el abrupto curso de la polémica. La primera tenía que ver con la lógica misma de la disputa que en definitiva se centraba en la política para consolidar la identidad cultural de la nación. Por lo mismo, la secuencia derivó en situar en el terreno de la discusión la relación adecuada entre "lengua y pensamiento" de una nación independiente. $Y$ con un tema ya trabajado por ambas partes y esencial para las mismas, en la reforma de la ortografía del castellano para que la identidad y pensamiento nacional se expresaran fielmente en la palabra escrita. Y ahí la polémica pública comenzó a desvanecerse dejando el asunto a las puertas de un tema postergado pero crucial: la alfabetización -el leer y escribir- de la

5 A partir de 1823 su preocupación se centra en el aspecto escrito de la lengua, específicamente en el ortográfico: de esa fecha son sus Indicaciones sobre la conveniencia de simplificar i uniformar la ortografía en América (1884: 381-394), seguido por Ortografía castellana de 1827 (1884: 395400), Ortografía de 1844 (1884: 401-416), Reglas de acentuación de 1845 (1884: 421-424), y Reformas ortográficas de 1849 (1884: 425-432); en 1832 publica un breve artículo sobre Gramática castellana, donde fija su posición respecto de cómo debe ser una gramática de la lengua materna o nativa, y en 1835, un extenso tratado sobre Principios de la Ortolojía i Métrica de la lengua castellana (1884: 3-229), seguido al año siguiente por sus Lecciones de Ortología y Métrica. Cfr. Claudio Wagner, Andrés Bello y la Gramática Castellana latinoamericana. Revista Electrónica Documentos Lingüísticos y Literarios, UACH., $\mathrm{N}^{\circ} 29$.

http:/ / www.humanidades.uach.cl/ documentos_linguisticos/sommaire.php?id=1167

6 Jaksic, La pasión por el orden, pp. 178 y sgtes. 
población. La segunda línea deja los discursos polémicos y pasa, con una celeridad inusual, a las iniciativas de prácticas políticas, y en lo inmediato a establecer un "nuevo mapa educacional". En enero de 1842, el Ministro de Justicia, Culto e Instrucción Pública Manuel Montt designa a Sarmiento Director de la Escuela Normal de Preceptores para formar a los maestros que enseñarán y multiplicarán las escuelas primarias. Al año siguiente Andrés Bello es designado primer Rector de la Universidad de Chile, cargo que conservará hasta su muerte. Entre sus primeras tareas, la Universidad a través de la Facultad de Filosofía y Humanidades tendrá a su cargo la dirección de las escuelas primarias y la redacción de sus reglamentos y programas de estudios. Por lo mismo, y por cierta afinidad conjunta, el Rector Bello invita a Sarmiento a formar parte de la Facultad, desde la que ambos colaboraron en proponer una reforma ortográfica que Bello había originalmente elaborado en Londres. Si uno analiza con cierta mirada que prioriza la política o polémica ejecutiva -no pública letrada- a la política o polémica discusiva -que es pública letrada-, el desenlace inmediato de esta controversia es muy singular. Primero, porque de empezar por la oposición de política literaria-clasicismo/ romanticismo- termina en la corrección ortográfica de la lengua escrita. Segundo, porque de la práctica de alta elaboración o el "arte de la escritura" se arriba al ejercicio elemental de empezar a eliminar la alta tasa de analfabetismo. Tercero, los acérrimos líderes contendientes -uno como autoridad máxima de la élite política cultural y el otro forzando las puertas para entrar a ese ámbito-, terminan llegando a un acuerdo solidario que marca la "nueva política educacional" y rubrica la jerarquía ya establecida. Andrés Bello como autoridad absoluta del poder político cultural y Sarmiento, como su nuevo funcionario-ilustrado, con una dignidad académica menor pero con funciones ejecutivas mayores: en el límite mismo que marca la diferencia entre el afuera de lo interno del proyecto educativo nacional: dirigir el proceso educativo que transfiriere a la mayoría de la población del bárbaro analfabetismo al civilizado alfabetismo. Finalmente la conclusión de esa polémica, y que constituye un foco central en la práctica de la política consistía en determinar qué enseñar a aquellos múltiples habitantes con una multitud de deberes; qué podría conferirles esa enseñanza: el posible derecho a ser ciudadano de esta nuevo república. 


\section{¿Quién es el ciudadano de la nueva nación? La segunda polémica: José Victorino Lastarria y Andrés Bello.}

Forma parte del patrimonio intelectual chileno -y de sus innumerables estudios- la polémica entre Lastarria y Bello que comenzó el 22 de septiembre de 1844. Y se realizó bajo el mayor marco político académico que enmarcó desde la fundación de la Universidad de Chile su primer rector Andrés Bello. En forma muy protocolar, Bello invitó a Lastarria quien fuera antes su destacado alumno y a quien había designado como uno de los diecinueve miembros fundadores de la Facultad de Filosofía y Humanidades- a convertirse en protagonista central de una ceremonia de alto nivel: abrir la tradición de los estudios históricos en el centro académico de la república. Lastarria presentó su tesis basada en que la nación debía avanzar en sus propios estudios históricos. La invitación de Bello era, en cierto modo, un provocativo desafío porque el Rector ya conocía la matriz del pensamiento de Lastarria definido en parte en su discurso inaugural de la Sociedad Literaria en 1842. Finalmente Lastarria presenta su tesis denominada Investigaciones sobre la Influencia de la Conquista y del Sistema Colonial de los Españoles en Chile ${ }^{7}$. Sabido es que en este histórico discurso Lastarria sostenía que la herencia de la colonia debía ser destruida y abolida para que Chile alcanzara su libertad, afán todavía por hacer pues si bien los primeros patriotas lograron la independencia, la república todavía era el producto no extirpado de siglos de servidumbre, efectos y aberraciones del pasado colonial. Y Lastarria enunciaba la tarea futura de la nación bajo el principio que no existe un "orden fatal" superior a la soberanía del juicio y voluntad que permite a los pueblos libres obrar su propio bien basado en las "lecciones que la experiencia le suministre" y transmitidas por el conocimiento histórico. Como era de esperar, Andrés Bello asume la defensa de la Madre Patria, en términos de una ilustración académica, pero esta vez al amparo de un poder republicano y portaliano que no desea alterar un orden civil y social ya constituido, muchas de cuyas bases descansan en el patrimonio colonial, aunque ahora un poco invisibles en el marco

7 José Victorino Lastarria, Investigaciones sobre la influencia social de la Conquista i del sistema colonial de los españoles en Chile. Memoria presentada a la Universidad de Chile en su sesión jeneral del 22 de septiembre de 1844, en cumplimiento del artículo 28 de la ley del 19 de noviembre de 1842. Santiago: Imprenta del Siglo, 1844. 
de un republicanismo que emerge como un socio confiable en el nuevo colonialismo del capitalismo occidental. $\mathrm{Y}$ algunas expresiones son notables por la firmeza de una política que se debe respetar:

La injusticia, la atrocidad la perfidia en la guerra, no han sido de los españoles solos, sino de todas las razas, de todos los siglos, [...] los españoles abusaron de su poder no con imprudencia, como dice el señor Lastarria, sino con miramiento a la humanidad, con el mismo respeto al derecho de gentes, que los estados poderosos han manifestado siempre en sus relaciones con los débiles ${ }^{8}$ (Silva Castro, 1969: 59).

Para agregar más adelante, "los débiles invocan la justicia: déseles la fuerza y serán tan injustos como su opresores". Sin embargo, entre las muchas plumas que desde ambos frentes argumentaron en el debate, surgió nuevamente una figura que reflejaba el cambio político, cultural y educativo de los años 40: Domingo Faustino Sarmiento, ahora como director de la Escuela Normal de Preceptores pero también como asiduo redactor de los medios de prensa, quien escribió su opinión sobre el tema, señalando que España había procedido con su colonias como Chile procedería con las suyas, sin otra diferencia que las que establecen las luces de la época y las diversas formas de gobierno. Y agrega - el antes controversial polemista de Bello y ahora el más fiel defensor de su causa que es también la suya- apuntando a la matriz del pensamiento e idioma demandante de Lastarria: "Ese lenguaje era excelente como medio revolucionario, pero treinta años después es injusto y poco exacto". Sarmiento, como diría Bourdieu, ha cambiado en pocos años tanto su posición como su ubicación en el campo del poder y en la construcción de su reproducción en Chile; por tanto, es un agente institucional cuyo habitus de apetencias había cambiado con su ritualización en la élite político-educativa, cuya autoridad máxima y siempre ascendente era Andrés Bello. Lo que había cambiado era su disposición confrontacional. Como señala Iván Jaksic:

Políticamente, Bello y Sarmiento estaban igualmente comprometidos con el orden portaliano, y con las políticas de Montt, pero diferían en cuanto a los métodos para conseguir 
los fines deseados. En temas tanto políticos como gramaticales, Bello era cauteloso y gradualista, mientras que Sarmiento creía en la acción rápida y decisiva" (Jaksic, 2001: 178 y sgtes.).

Pero si bien la posición y ubicación de Sarmiento cambió, el debate sobre la historia precedente continuaba. Pocos años más tarde, Lastarria envió su segunda arremetida sobre el mismo tema y al mismo centro: su ensayo Bosquejo histórico de la Constitución del Gobierno de Chile durante el Primer Periodo de la Revolución fue presentada para un concurso abierto por la Universidad de Chile en 1847. La comisión integrada por Antonio Varas -que había sido compañero de aulas de Lastarria-, y García Reyes, si bien le otorgó el premio a Lastarria planteó, en anexo aparte, sus conclusiones, indicando que dicha comisión apreciaba un ensayo de generalizaciones sugerentes pero, subrayaba, carente de cualquier evidencia documental. La estimación de Varas y García Reyes no podía ser menor. Como en otras partes, Lastarria insistía en que Chile seguía atrapado entre "la historia de una época pasada que puede el filósofo someter sin gran dificultad a sus investigaciones, y la de una época nueva que tocamos y nos pertenece porque es la presente". Esta nueva polémica se torna más intensa básicamente porque la tensión política entre conservadores y liberales recrudece, entre otras razones, por el influjo que acarrea la obra de dos extremos "liberales románticos" a saber, Francisco Bilbao y Santiago Arcos. Pero ¿qué se jugaba en el fondo de esta nueva polémica? Siguiendo a continuación, sólo en parte, el análisis realizado por Álvaro Kaempfer ${ }^{10}$, afirmamos que las polémicas institucionales de 1844 y de 1847 abordan en principio un tema que en esa época conmocionaba a un Occidente posterior a la Revolución Francesa y a la Ilustración: cuál era el tipo de "Historia" que debía renovar o inventar las nuevas repúblicas marcadas, más o menos, por el capitalismo emergente y su teoría simbólica del liberalismo. En Chile tardíamente, como en toda república periférica, el debate se abrió en la década de los 40. Y como ya lo hemos señalado, la disputa confrontaba al bipolarismo en escena: el grupo dominante de los conservadores-

9 Enzo Faletto y Julieta Kirkwood, Sociedad burguesa y liberalismo romántico, Caracas: El Cid Editor, 1977.

10 En este punto seguimos solo algunos puntos del artículo de Kaempfer. Con todo valoramos la amplia y reciente bibliografía que el autor tiene a la vista, si bien sus fines y objetivos se distancian y oponen a los muestros. Kaempfer, Álvaro. 2006. "Lastarria, Bello y Sarmiento en 1844: Genocidio, historiografía y Proyecto Nacional", en Revista de Crítica Literaria Latinoamericana, año XXXII, Nos 63-64. Lima-Hanover, $1^{\circ}$ y $2^{\circ}$ semestres, pp. 9-24.[ Links ] 
portalianos y el nuevo liberalismo ilustrado que entraba en oposición en el centro intelectual de la política: la universidad como privilegiado "círculo de la academia humanista".

Pero como anexo indisoluble al tema en debate existió otro eje con una triple arista: primero ¿quién era el sujeto que acreditaba los méritos o condiciones suficientes para ejercer la nueva historia?; segundo ¿cuál era el sujeto central que movía la historia pasada? Y finalmente ¿qué posición tendría el "nuevo historiador" frente a la anterior historia? En esos términos, la convicción asumida y expresada por Lastarria colisionaba frontalmente con la autoridad que gobernaba y dominaba el centro intelectual y la sociedad chilena. Sus respuestas a las preguntas anexas eran elocuentes. El historiador de la nueva época debía ser antes que nada un liberal que mirara hacia el futuro desde la perspectiva europea; el sujeto central que movía la historia pasada era el colonialismo hispánico; y frente a esa historia reciente, dominante y depredadora de toda libertad, la nueva historia debía negarla sin exclusiones y sólo reivindicar a los sujetos que resistieron con tenacidad a su ser dominados. Sin embargo, Lastarria hacía visible lo que ya estaba en la mira de todos en el nuevo escenario chileno. Si bien los independentistas alcanzaron su objetivo de una nación republicana, su aspiración falló en el cumplimento final: la libertad de la nación seguía siendo dominada por los vínculos coloniales que aún subsistían en sus herederos republicanos. Años después, en su Memoria, Lastarria es más elocuente: “el cañón de Chiloé anunció al mundo que estaba terminada la revolución de la independencia política i principiaba la guerra contra el poderoso espíritu que el sistema colonial inspiró a nuestra sociedad"11 (Anales, 1846: 266). Y al interior de las polémicas, su intención política era directa: buscar en el pasado colonial la tormenta emancipadora que inaugurara el futuro.

De esta manera, el "nosotros" al que apelaba Lastarria para asumir un "presente que nos pertenece" y forjar una nueva historia, nacía de la voluntad de emancipación legada por la resistencia indígena. Por lo mismo, y pese a que Lastarria aceptaba que, "a pesar de haber sido sepultados por un orden erigido sobre los escombros de su resistencia, los araucanos legaron una voluntad de redención política que ahora nutría el discurso de emancipación nacional" (ídem). Y es en ellos, en los araucanos y en su voluntad emancipadora, que Lastarria encuentra,

11 Anales de la Universidad de Chile, años 1843- 1844. Santiago, Imprenta del Siglo, Octubre de 1846.

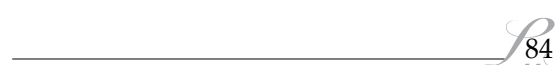


al principio, al sujeto ya aplastado, que hay que redimir históricamente, para forjar sujeto actual que libere la dominación que sigue imperando en la república.

Por cierto que esa visión -enconadamente provocativa- fue refutada de inmediato por Andrés Bello. Primero, por su valoración clásica de lo hispanista-colonial que a través de esa vía incluyó a Chile a la matriz de la cultura occidental. Segundo, y en nuestra perspectiva, porque bajo esa elaborada racionalidad, se acreditaba que el sólido piso portaleano -donde el propio Bello con Montt eran ahora su líderes de facto- , seguía la cultura occidental, más allá de las alteraciones precipitadas que podían desajustar el orden republicano ya ganado. Tercero, porque sin menospreciar por sí mismo a los indígenas, era imposible avanzar en el proyecto nacional de progreso y bienestar, interfiriendo ese camino con pueblos absorbidos por la cultura clásica occidental, incluso en la entrada del nuevo mundo occidental. En palabras de Kaempfer, a partir de estas presunciones, Bello afirmó, que el único vestigio indígena en el futuro serán "unas pocas palabras naturalizadas en los idiomas advenedizos, y monumentos esparcidos a que los viajeros curiosos preguntarán en vano el nombre y las señas de la civilización que les dio el ser" (Kaempfer, 2006: 19). A ello se sumó sin templanzas Sarmiento, quien hacia la misma fecha, 1845, había publicado Civilización y barbarie. Fuera de adherir totalmente a la posición de Bello sobre la incompatibilidad existente entre proyecto nacional y población indígena, las expresiones del director de la Escuela Normal de Preceptores, fueron de algún modo implacables: "al exterminar [los españoles] a un pueblo salvaje cuyo territorio iban a ocupar hacían simplemente lo que todos los pueblos civilizados hacen con los salvajes". Y Kaempfer comenta:

$\mathrm{Su}$ fórmula "absorbe, destruye, extermina" tenía claro que podía "ser muy injusto exterminar salvajes, sofocar civilizaciones nacientes, conquistar pueblos que están en posesión de un terreno privilegiado". Sin embargo, se permitió aclarar de inmediato que, "gracias a esta injusticia la América, en lugar de permanecer abandonada a los salvajes, incapaces de progreso, está ocupada hoy por la raza caucásica, la más perfecta, la más inteligente, la más progresiva de las que pueblan la tierra. (15-16) 
Sin embargo, en esta "búsqueda de un sujeto reivindicado en pasado colonial" para "forjar un nuevo sujeto actual" que liberara al Chile republicano de la dominación colonial heredada, Lastarria se iba despojando del inicial araucano con fines de diseñar un sujeto más funcional. Si bien reconocía su afán liberador, "infatigable viajero, ciego amante de su independencia", advierte su naturaleza algo inquieta: "carácter soberbio, independiente, valeroso, inconstante, disimulado, irritable, poco jovial i siempre taciturno". Con todo, Lastarria posee otras cartas en el devenir colonial. Al respecto señala que el territorio chileno se vio "aumentada con la de los mulatos i zambos", que muy pronto "se multiplicó tan prodijiosamente, que a fines del siglo pasado formaba la mayoría de la población criolla". Finalmente, Lastarria además de contar con el araucano, considera también otra variedad de sujetos del pasado reciente para interpelar a la época republicana: mestizo, criollo, popular subalterno. Toda esta laboriosa tarea hacia el pasado para encontrar un sujeto capaz de enfrentar el presente, deriva en que el pueblo -en sus diferentes fisonomías étnicas y mestizas- era el único agente capaz de desmontar el colonialismo que seguía imperando en la sociedad republicana. Pero ¿qué resultado quedaba de esta disputa que sostenía Lastarria ante a Bello y Sarmiento, ante los conservadores y frente al propio liberalismo? Este debate ponía en juego un proceso de identificación cultural chilena y latinoamericana. Proceso nada fácil tanto para nuestra nación como para América Latina. En ese sentido, somos partes de los términos y del cuadro de Alberto Moreiras, pues esta búsqueda se transforma en una "pesadilla de la violenta homogeneización, uniformización y represión de sociedades múltiples y diferenciales... [que] desmiente la potencialidad liberadora de la identidad nacional concebida como el primer espacio de la literatura latinoamericana desde la Independencia ${ }^{12 \prime \prime}$ para la literatura, ciertamente, pero también para la política inmediata y de largo plazo durante todo el XIX. Porque ¿qué había al frente como sujeto dominador de toda la sociedad y del ímpetu opositor del nuevo liberalismo? La identidad autoritaria del ayer colonial y del ahora republicano pero bajo el capital simbólico aportado por Bello de un progreso ilustrado y, por ende, moderado.

12 Moreiras, Alberto. Tercer espacio: literatura y duelo en América Latina. Santiago de Chile: LOM Ediciones, 1999. Citado en Kaempfer, OB. Cit. 
Según la Constitución de 1830, son ciudadanos las personas chilenas que gozan de alfabetismo y de ciertos bienes materiales medidos por su tributación. Y en la primera de las condiciones de la ciudadanía chilena: ser alfabeto, ¿a quiénes se debe educar? A todo sujeto que con la edad suficiente sepa leer y escribir. Y ese derecho lo hace posible la república chilena hacia la década de 1840.

En este escenario de debates, examinar el despliegue educativo nos permite establecer que los límites del periodo para educar eran de máxima estrechez. Por una parte, porque el grupo dominante se movía casi bajo la sombra del poder colonial; por otra, porque el grupo opositor de los liberales ilustrados no atinaba certeramente a diseñar al sujeto o agente de cambio para transformar la dominación del pueblo, y solo se amparaba en una vacía noción de pueblo bajo la variedad de su identidad étnica: criollo, mestizo, zambo, mulato, y ya dejando a un lado al "araucano" y su voluntad de rebelión política y frente al cual la república chilena de la década de 40 combate sin pausa. ¿Qué nos ofrecen entonces las grandes polémicas entre grandes intelectuales, examinadas brevemente, que directa o indirectamente influyen sobre la educación después de 30 años de la independencia? En principio, muy poco. Primero, la ortografía sobre la lengua castellana escrita. Segundo, ningún control ni obligación para cumplir con el derecho del ciudadano: saber leer y escribir. 


\section{Bibliografía}

Anales de la Universidad de Chile. Discursos. "Anales de la Universidad de Chile" 1842, 1843, 1844, 1845, 1846. [En línea]

Bello, Andrés. (1841) Diario El Araucano. Santiago: Archivo Nacional.

Bourdieu, P. y Wacquant, L. (1995) Respuestas. Por una Antropología reflexiva. México: Grijalbo.

Edwards, Alberto. (1928) La Fronda aristocrática. Santiago de Chile: Imprenta Nacional.

Enzo Faletto y Julieta Kirkwood. (1977) Sociedad burguesa y liberalismo romántico. Caracas: El Cid Editor.

Góngora, Mario. (1981) Ensayo histórico sobre la noción de Estado en Chile en 1os siglos XIX y XX. Santiago de Chile: Ediciones La ciudad.

Hurtado, Edda. Cronología de educación/literatura/política del siglo XIX, elaborado para el Proyecto Fondecyt [20132014]: Literatura y Educación: continuidades y rupturas en la progresiva conformación de un discurso específico acerca de la enseñanza literaria en Chile en los inicios del sistema republicano (1842-1893).

Jaksic, Iván. (2001) Andrés Bello. la pasión por el orden, Santiago, Editorial Universitaria.

Kaempfer, Álvaro. (2006). Lastarria, Bello y Sarmiento en 1844: Genocidio, historiografía y Proyecto Nacional, en Revista de Crítica Literaria Latinoamericana, año XXXII, Nos 6364. Lima-Hanover, $1^{\circ}$ y $2^{\circ}$ semestres

Lastarria, José Victorino. (1844) Investigaciones sobre la influencia social de la Conquista $i$ del sistema colonial de los españoles en Chile. Memoria presentada a la Universidad de Chile en su sesión jeneral del 22 de septiembre de 1844, en cumplimiento del artículo 28 de la ley del 19 de noviembre de 1842. Santiago: Imprenta del Siglo. 
Moreiras, Alberto. Tercer espacio: literatura y duelo en América Latina. Santiago de Chile: LOM Ediciones, 1999.

Portales, Diego. Carta a Antoni Garfias. Santiago: 14 de diciembre de 1831.

Sarmiento, Domingo Faustino, Diario El Mercurio, 27 de abril de 1842. Santiago: Archivo Nacional.

Serrano, Sol, Ponce de León, M y Rengifo, F. (Editoras). (2012) Historia de la educación en Chile. 1810-2010. Aprender a leer y a escribir (1810-1880). Vol. I. Santiago de Chile: Aguilar chilena de ediciones, S.A.

Silva Castro, Raúl. (1969) Literatura Crítica de Chile, Santiago: Editorial Andrés Bello.

Stuven, Ana María. (2000) La seducción de un orden. Las elites y la construcción de Chile en las polémicas culturales y políticas del siglo XIX. Santiago: Ediciones de la Universidad Católica de Chile. 